\title{
Relação entre ponto de ruptura e padrão morfométrico em deslizamentos, bacia hidrográfica do Rio Rolante - RS
}

\author{
Relations between landslide breaking points and morphometric patterns, River Rolante hydrographic basin - RS
}

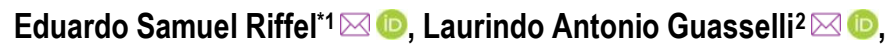 \\ Luis Fernando Chimelo Ruiz ${ }^{\square}$ (1), Samuel Gameiro² $₫$ (1)
}

\author{
1Departamento de Geografia, Instituto de Geociências, Universidade Federal do Rio Grande do \\ Sul, Porto Alegre, Rio Grande do Sul, Brasil \\ 2Programa de Pós Graduação em Sensoriamento Remoto, Universidade Federal do Rio Grande \\ do Sul, Porto Alegre, Rio Grande do Sul, Brasil \\ E-mail: laurindo.guasselli@ufrgs.br (LAG); ruiz.ch@gmail.com (LFCR) ; \\ samuel_gameiro@outlook.com (SG) \\ *E-mail para correspondência: edriffel@gmail.com
}

Recebido (Received): 02/02/2021 Aceito (Accepted): 10/08/2021

Resumo: Grande parte dos deslizamentos no Brasil são relacionados a eventos pluviométricos extremos, ao tipo e espessura de solo e às características do relevo, e frequentemente causam perdas sociais e danos econômicos. O presente trabalho teve como objetivo analisar a relação entre pontos de ruptura (coroa) e parâmetros morfométricos de deslizamentos, relativos a um evento hidrometeorológico extremo, na bacia hidrográfica do Rio Rolante - RS. A partir de imagens SRTM 30m, foram obtidos dados de declividade, elevação, curvatura horizontal e vertical e aspecto. Com base no mapeamento foram obtidos 143 pontos de ruptura em cicatrizes de deslizamentos. Utilizando agrupamento K-means foram identificados padrões morfométricos relacionados aos pontos de ruptura, e gerados perfis de vertentes. Os resultados mostram 4 tipos de vertentes na bacia do rio Rolante, com ocorrência de processos de deslizamentos. Perfis côncavos e convergentes tiveram menor ocorrência, e perfis convexos e divergentes apresentaram maior ocorrência. Com base nas médias dos principais agrupamentos de clusters, a declividade e as curvaturas tiveram a maior importância em relação à localização das rupturas na vertente, e foram importantes condicionantes de suscetibilidade aos deslizamentos. As médias dos agrupamentos ocorreram acima de $30^{\circ}$ de declividade no agrupamento com 4 clusters, que foi o mais representativo.

Palavras chave: Movimentos de massa; K-means; Declividade; Curvatura de vertentes.

Abstract: Landslides in Brazil are related to extreme rainfall events, soil type and thickness, and relief characteristics, and often cause social losses and economic damage. This study aimed to analyze the landslides related to an extreme hydrometeorological event, in the Rolante River Basin - RS, and to relate breaking points and morphometric parameters of these landslides. From SRTM 30m images, data on the slope, elevation, horizontal and vertical curvature and appearance were obtained. Based on the mapping, 143 rupture points in sliding scars were obtained. Using K-means grouping, morphometric patterns related to the breaking points were identified, and slant profiles were generated. The results show 4 types of slopes in the Rolante River basin, with the occurrence of landslide processes. Concave and convergent profiles had fewer occurrences, and convex and divergent profiles had more occurrence. Based on the averages of the main cluster groupings, the slope and curvatures had the greatest importance in relation to the location of the slope ruptures, which were important determinants of susceptibility to landslides. The averages of the clusters occurred above $30^{\circ}$ of slope in the cluster with 4 clusters, which was the most representative.

Kaywords: Mass Movements; K-means; Slope; Plan Curvature.

\section{Introdução}

Inventários de ocorrências de deslizamentos trazem informações sobre a localização de deslizamentos de terra e a sua espacialização são importantes ao definir metodologias para avaliar padrões e dinâmicas desses processos (LIN et al., 2010; VAN DEN EECKHAUT; HERVÁS, 2012; FROUDE; PETLEY, 2018). Além 
disso, os zoneamentos são ferramentas indispensáveis para reduzir riscos para as atividades humanas (VAN WESTEN et al., 2006; LACASSE et al., 2010). Os desastres desencadeados por esses eventos, frequentemente causam perdas econômicas e danos substanciais (NADIM et al., 2006; HONG et al., 2007; ZHAO et al., 2019). A dinâmica das vertentes é fundamental na compreensão dessa dinâmica geomorfológica (KIRKBY,1988; ZÊEZRE, 2005).

Deslizamentos são movimentos descendentes de material em declive desencadeados por chuvas fortes, ou causados e intensificados por atividades antrópicas (HIGHLAND; BOBROWSKY, 2008; GUZZETTI et al., 2012), ou agentes independentes como água (BIGARELLA et al., 2003). São desencadeados por fatores relacionados às características locais (WANG, 2017), mas também estão relacionados a eventos climáticos extremos (GARIANO; GUZZETTI, 2016; LEE, 2017; ALI et al., 2020). Os deslizamentos, constituem-se em fenômenos de ocorrência natural em encostas mais suscetíveis, com declividades acentuadas (ÇELLEK, 2020) e características geológicas e geomorfológicas que favorecem o deslocamento de terras (ALCÁNTARA-AYALA, 2002; AVANZI et al., 2004; KOBIYAMA et al., 2004; LOPES, 2006; CHANG et al., 2018; DAMAYANTI et al., 2020).

Segundo Highland e Bobrowsky (2008), a previsão de deslizamentos deve identificar e estimar as condições e processos que promovem a instabilidade e suas contribuições relativas à ruptura do declive. A morfologia de encostas, tanto em planta quanto em perfil, pode revelar zonas preferenciais de deslizamentos e indicar cicatrizes (FERNANDES et al., 2001; HARIST et al., 2018). Essas zonas preferenciais seriam as porções de taludes com formas convergentes de relevo (WOOTEN et al., 2016), mais suscetíveis a deslizamentos devido à concentração de fluxo das águas (HUNGR et al., 2001; IVANOV et al., 2020).

Um deslizamento pode ser dividido em segmentos (Figura 1) (VARNES, 1978; GUIDICINI; NIEBLE, 1984). Em mapeamentos de deslizamentos com objetivo de gerar mapas de áreas suscetíveis (FERNANDES et al., 2001; ERENER; DÜZGÜN, 2012; PSOMIADIS et al., 2020), os pontos de ruptura (coroa) de deslizamentos devem ser identificados em escalas de detalhe, utilizando imagens de alta resolução espacial (LEE; CHOI, 2004; AMATYA et al., 2019) e inventários detalhados (GUZZETTI et al., 2012).

A característica do relevo é, possivelmente, o determinante do ponto de ruptura das ocorrências de deslizamentos (VARNES, 1978; GUIDICINI; NIEBLE, 1984). No modelo de vertente proposto por Dalrymple et al. (1968) os deslizamentos, geralmente, ocorrem a partir da Unidade de Vertente 4, e os processos de rastejos na Unidade 3 (Figura 1), Rastejo (creep) é o nome informal dado ao fluxo lento de terra e consiste em um movimento vagaroso, imperceptível e contínuo, para baixo do solo que forma o talude, enquanto o deslizamento consiste em um fluxo de terra rápido (VARNES, 1978; GUIDICINI; NIEBLE, 1984).

A correlação entre declividade de encostas e deslizamentos vem sendo estudada há bastante tempo (GUIDICINI; NIEBLE, 1984, CONSTANTIN et al., 2011; ARMAŞ, 2012; CERRI et al., 2017). Nem sempre as encostas de maior declividade são as mais instáveis, a análise de diversos deslizamentos indica que a maioria ocorre em taludes de declividade mediana $\left(20^{\circ}-35^{\circ}\right)$ após eventos extremos de precipitação (SALTER et al., 1981). Segundo Sjöberg (2000), "mecanismos de ruptura em taludes altos, especialmente em rochas duras e em rochas fraturadas, são geralmente pouco entendidos e/ou conhecidos", sendo necessário conhecer (a) as condições para ocorrência de diferentes rupturas; (b) as condições para a deflagração da ruptura; e (c) a forma e a localização da superfície de ruptura.

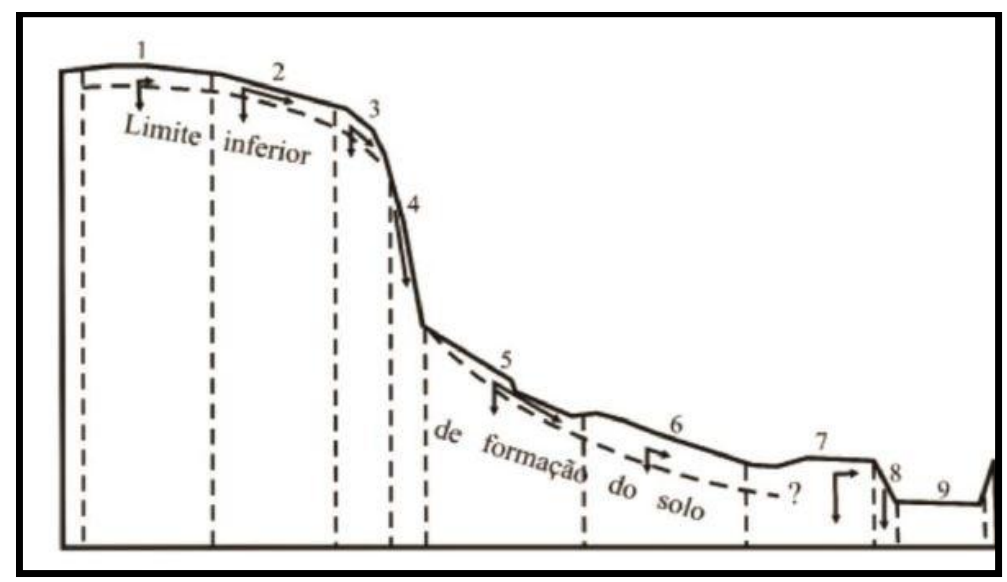

Figura 1. Modelo de vertente explicitando as unidades de vertente e os processos geomórficos dominantes. Fonte: Dalrymple et al. (1968). 
A Figura 1 apresenta o modelo de vertente elaborado por Dalrymple et al. (1968). Segundo os autores uma vertente possui 9 segmentos: 1. Interflúvio $\left(\mathbf{0}^{\mathbf{0}}-\mathbf{1}^{\mathbf{0}}\right)$ : Processos pedogenéticos associados com movimento vertical da água superficial; 2. Declive com Inflitração $\left(\mathbf{2}^{\mathbf{0}} \mathbf{-} \mathbf{4}^{\mathbf{0}}\right)$ : Eluviação mecânica e química pelo movimento lateral da água subsuperficial; 3. Declive convexo com rastejo: Rastejo e formação de terracetes; 4. Escarpa (ângulo mínimo de $\mathbf{4 5}^{\circ}$ ): Desmoronamentos, deslizamentos, intemperismo químico e mecânico; 5. Declive intermediário de transporte: Transporte de material pelos movimentos coletivos do solo; formação de terracetes; ação da água superfdicial e subsuperficial; 6. Sopé coluvial (ângulos entre $\mathbf{2 6}^{\mathbf{0}}$ $\mathbf{e ~ 3 5}^{\circ}$ ): Reposição de material pelos movimentos coletivos e escoamento superficial; formação de cones de dejeção; transporte de material; rastejo; ação superficial da água; 7. Declive aluvial $\left(0^{\mathbf{0}}-4^{\mathbf{o}}\right)$ : Deposição aluvial; processos oriundos do movimento subsuperficial da água; 8. Margem de curso de água: Deslizamento; desmoronamento; 9. Leito do curso de água: Transporte de material para jusante pela ação da água superficial; gradação periódica.

A classificação setorial de deslizamento proposta por Varnes (1978) e modificada por Cruden; Varnes (1996) define o ponto de ruptura como coroa (crown) que se localiza acima da escarpa principal (main scarp). Nesse estudo, utilizamos a expressão ponto de ruptura de um deslizamento como correspondente à coroa. Segundo Varnes (1978) a coroa consiste, em material não deslocado, e adjacente às partes mais altas da escarpa principal (Figura 2).

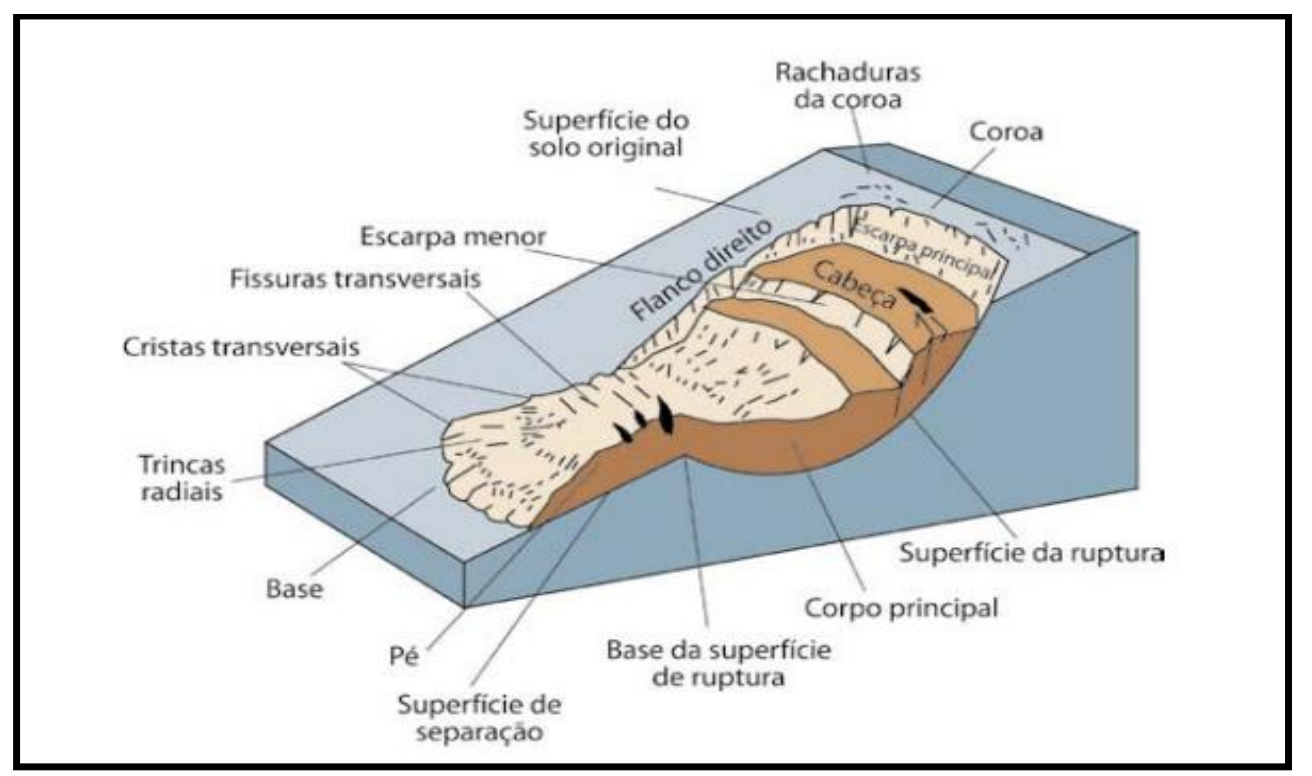

Figura 2. Nomenclatura comumente usada para definir as partes de um deslizamento. Fonte: Adaptado de Varnes (1978).

Segundo Marangon (2009) uma característica em deslizamentos é a parte superior escorregada (próximo a crista), um plano vertical até uma determinada profundidade, onde geralmente se inicia o deslizamento. Estes planos são aproximadamente coincidentes com a profundidade das trincas de tração (fendas). De acordo com Costa Nunes (1992) além da influência da água, das propriedades dos materiais e das tensões internas, a forma do talude e a geometria da ruptura são decisivas para a ocorrência de deslizamentos.

Variáveis geomorfométricas têm sido utilizadas para identificar áreas suscetíveis a deslizamentos (MOORE et al., 1991; HEARN, 1992; LARA et al., 1997; OHLMACHER; DAVIS 2003; AYALEW; YAMAGISHI, 2005; GUZZETTI et al., 2005; WOOD; MOSCARDELLI, 2005; KAMP et al., 2008; YALCIN, 2008; REGMI et al., 2010; VANACÔR; ROLIM, 2012; RIFFEL; RUIZ; GUASSELLI, 2016; OLIVEIRA et al., 2018; GAMEIRO et al., 2019; QUEVEDO et al., 2019), no entanto, os deslizamentos são processos complexos e podem ocorrer devido à combinação de diversos fatores.

Classificar elementos em grupos requer a manipulação de uma base de dados volumosa, o que dificulta a análise de combinações de grupos. A análise de cluster busca agrupar elementos baseando-se na similaridade entre eles (MACHADO, 2014, WANG et al., 2017; WAN et al., 2018; TANG et al., 2020). A função do algoritmo é fornecer uma classificação baseada em análises e comparações entre os seus valores numéricos através de uma classificação de aprendizado sem a necessidade de supervisão (KANUNGO et al., 2002; LIKAS et al., 2003; DING; HE, 2004). 
Assim, esse trabalho tem como objetivo analisar a relação entre padrões morfométricos e pontos de ruptura de deslizamentos a partir de agrupamento K-means.

\section{Caracterização da área de estudo}

Como área de estudo foi adotada a bacia do rio Rolante, uma sub-bacia do rio dos Sinos, com área de 816 $\mathrm{km}^{2}$ (Figura 3). A bacia abrange os municípios de Rolante, Riozinho e São Francisco de Paula. Suas nascentes e cabeceiras localizam-se no município de São Francisco de Paula, aproximadamente a $150 \mathrm{~km}$ de Porto Alegre, e sua foz no rio dos Sinos, aproximadamente a $100 \mathrm{~km}$ de Porto Alegre. A bacia possui, no geral, alta declividade, chegando a $70^{\circ}$ nas áreas de encosta (LUERCE, 2015).

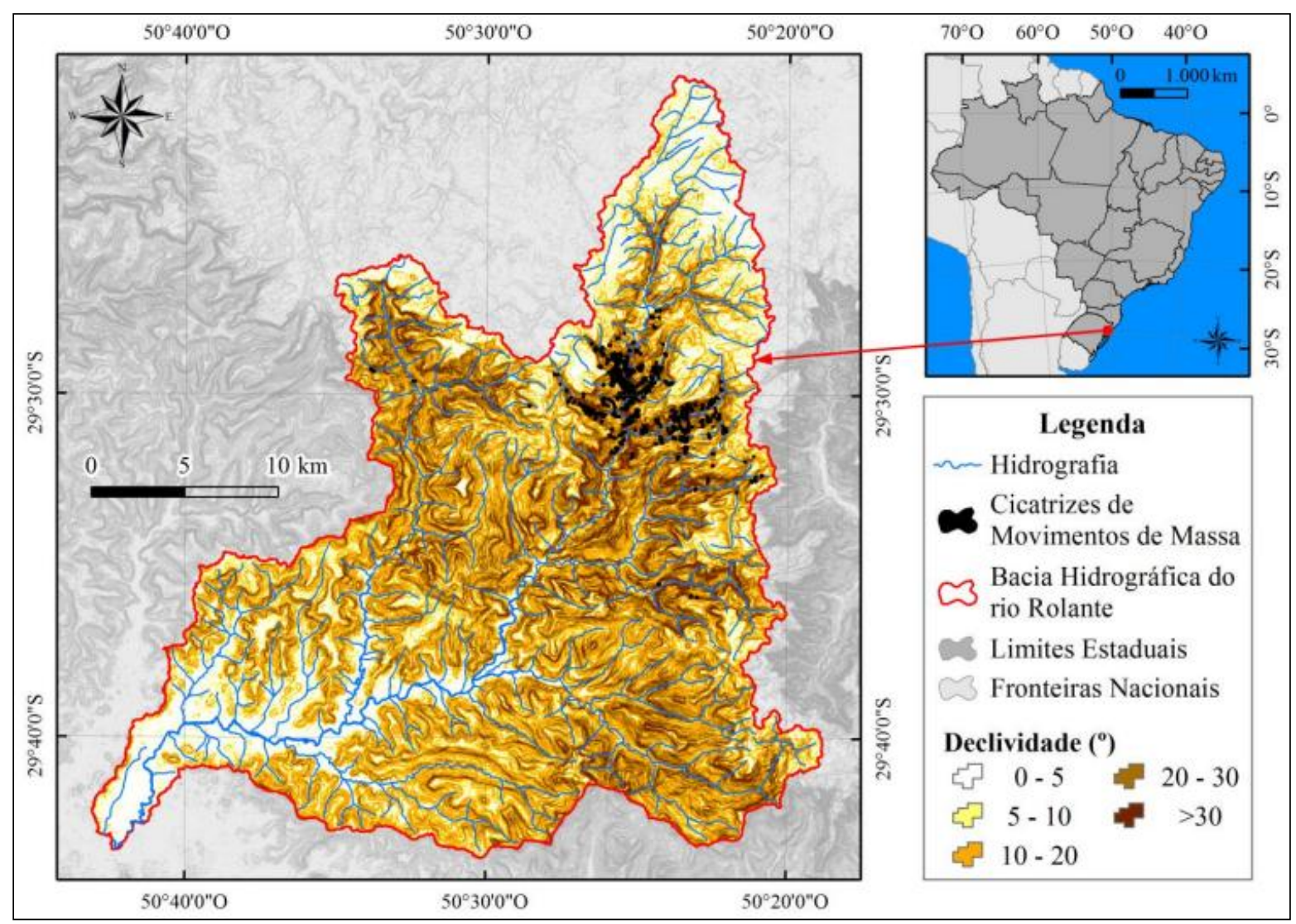

Figura 3. Mapa de localização da bacia hidrográfica do rio Rolante, de variação de declividade e de cicatrizes de movimentos de massa. Fonte: Quevedo, 2019

A geologia se insere na Bacia do Paraná, com derrames vulcânicos de natureza predominantemente básica (basaltos) e ácida (riolitos, dacitos) caracterizados pela Formação Serra Geral. Os processos de sedimentação mais recentes são: (a) depósitos Colúvio-Aluviais: formados por conglomerados, arenitos conglomeráticos, arenitos, siltitos e lamitos maciços, ou com laminação plano-paralela e estratificação cruzada acanalada; (b) depósitos Aluviais relacionados a Barreiras Holocênicas e Pleistocênicas, compostas por areia grossa a fina, cascalho e sedimento síltico-argiloso, em calhas de rio e planícies de inundação. A Formação Serra Geral corresponde ao grupo São Bento da bacia Sedimentar do Paraná, formado durante a Supersequência Gondwana III, composta por derrames de basalto, basalto andesitos, riodacitos e riolito, onde se intercalam arenitos intertrápicos Botucatu na base e sedimentos vulcanogênicos da porção mediana ao topo da sequência. São encontradas as unidades geológicas Fácies Várzea do Cedro, Fácies Caxias e Fácies Gramado (LUERCE, 2015).

A geomorfologia, de acordo com Luerce et al. (2013), se caracteriza pelas regiões geomorfológicas da Planície Continental, da Depressão Central Gaúcha e do Planalto das Araucárias. Abrange também as Unidades Geomorfológicas da Planície Alúvio-Coluvionar, Planalto dos Campos Gerais, Serra Geral, Patamares da Serra Geral e Depressão do Rio Jacuí. (LUERCE et al., 2013)

A Tipologia Climática é dividida em: (a) Subtropical III: medianamente úmido; (b) Subtropical IVb: muito úmido (ROSSATO, 2011). As chuvas o correm em todas as estações do ano, com valor médio anual de $1500 \mathrm{~mm}$ nas regiões baixa, e $2468 \mathrm{~mm}$ anuais nas áreas mais altas $(981 \mathrm{~m})$ nas nascentes do rio Rolante. 
O solo predominante na região é o Neossolo Litólico, solo pouco espesso que ocorre em relevos mais acidentados e dissecados, e ocorrem também Cambissolos húmicos e Argissolos (SEMA, 2017).

Um fenômeno hidrometeorológico extremo ocorreu em 05 de janeiro de 2017, no município de Rolante. Após precipitações intensas e concentradas, ocorreram enxurradas e centenas de deslizamentos que, ao convergirem para o canal, se transformaram em fluxos de detritos na região do Alto Sinos, em especial, na bacia do rio Mascarada (Figuras 4 e 5). O rio Mascarada é um afluente do rio Rolante, inserido na bacia dos Sinos (SEMA e GPDEN/IPH/UFRGS, 2017). O município de Rolante foi o mais afetado, com interrupção de vias e abastecimento de água, e prejuízos estimados em R 70 milhões (PAIXÃO et al., 2017).
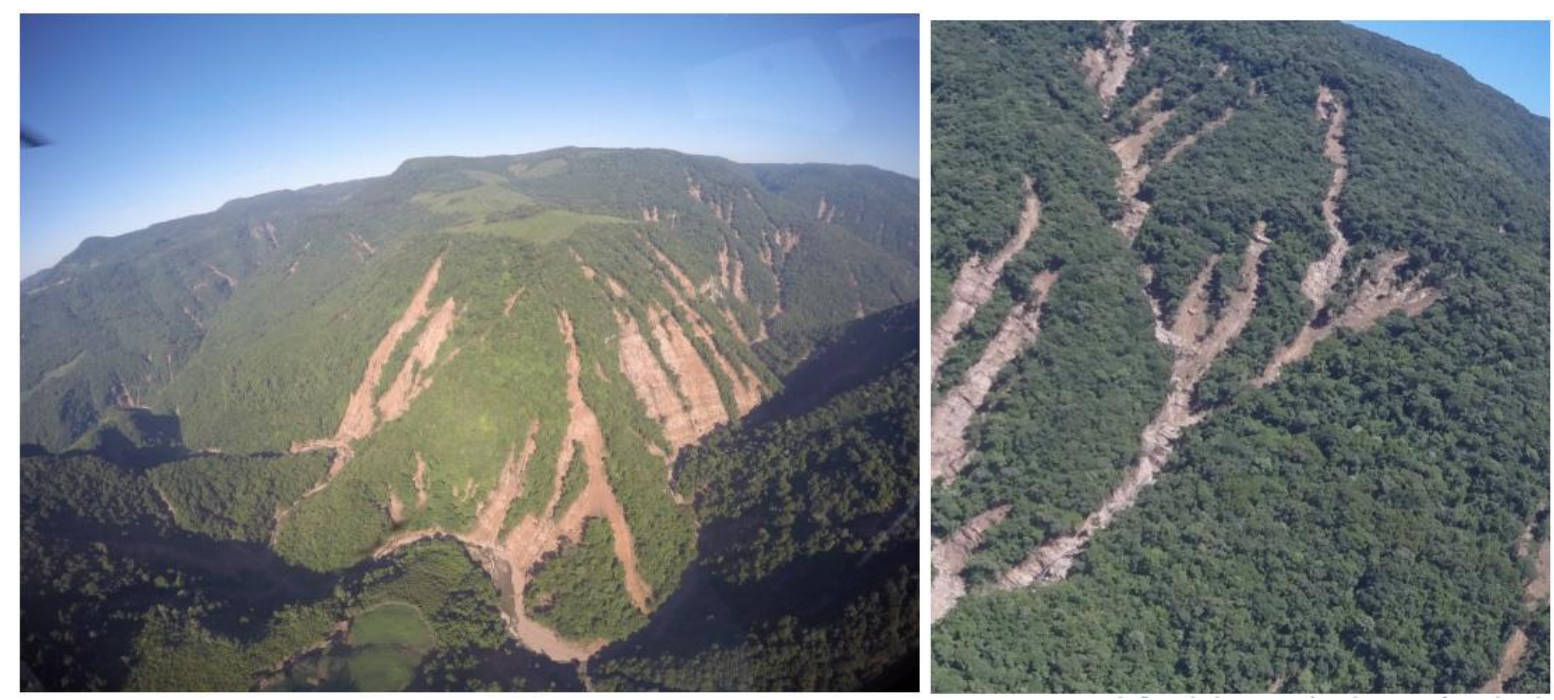

Figuras 4 e 5. Cicatrizes de deslizamentos, de 05 de janeiro de 2017, município de Rolante - RS. Fonte: Secretaria do Ambiente e Desenvolvimento Sustentável-RS, 2017. Nota: Grande parte das cicatrizes se localiza próximo as nascentes do rio Rolante, em formas de relevo bastante abruptas com vales fluviais bem aprofundados, solos pouco profundos em áreas com densa cobertura florestal característica da Mata Atlântica.

Esse evento, de extrema precipitação, ocorreu devido ao sistema de baixa pressão, associado ao relevo da região (SEMA, 2017). As áreas de instabilidade foram alimentadas por umidade e calor, que ganharam força suficiente para organizar uma massa de ar quente e úmida que ao se deparar com a serra, foi forçada a subir ocasionando chuvas localmente fortes. Pluviômetros locais indicaram volumes entre $100 \mathrm{~mm}$ e $180 \mathrm{~mm}$, em poucas horas. Não é possível estabelecer valores precisos em relação à precipitação devido à falta de estações de medição na área da bacia hidrográfica (SEMA, 2017).

Esses deslizamentos constituem-se em ameaça para uma parcela significativa das populações que ocupam as encostas íngremes, ou próximas a estas. Mesmo com esses indicadores e o registro de desastres, não existem inventários detalhados dos eventos o que acarreta numa deficiência de bases de dados sobre esses eventos adversos.

\section{Materiais e métodos}

Foi utilizado um inventário e um mapeamento com 297 cicatrizes, entre deslizamentos e corridas de detritos elaborados por Quevedo (2019), que utilizou imagens Sentinel 2, com resolução espacial de 10 m, e imagens disponibilizadas pelo programa Google Earth Pro. As datas de imagens mais próximas temporalmente do evento foram de 06 e 24 de agosto de 2017.

Conforme Prieto (2018) é importante diferenciar os tipos de movimentos de massa quando do seu mapeamento relacionado à sua gênese e ao Fator de Segurança (FS). De acordo com a NBR 11.682, FS trata da resistência de materiais, e não considera movimentos de massa de menor potencial de ruptura da encosta, como rastejos, quedas e rolamentos de blocos (ABNT, 2009). Para Domej et al. (2020), é importante diferenciar deslizamentos de outros tipos de movimentos de massa.

A partir de imagens orbitais e das cicatrizes de movimentos de massa, o trabalho selecionou somente as cicatrizes com características de deslizamentos. Nessas cicatrizes de deslizamento, foram identificados os pontos de ruptura (coroa), foi considerado o ponto superior de ruptura de cada cicatriz de deslizamento, a 
partir de análise visual das imagens orbitais. Buscou-se padronizar as condições morfométricas das cicatrizes em relação à gênese da sua ocorrência, diferenciando-se os deslizamentos do tipo planar, dos fluxos de detritos, que são os dois tipos principais de ocorrência na região. Os deslizamentos da região possuem um comprimento menor, e se iniciam em determinada porção da vertente, e se estendem até a base da vertente. Os fluxos de detritos possuem uma maior magnitude, e percorrem uma distância maior, seguindo muitas vezes direções de trechos de drenagem.

Utilizou-se dados da Shuttle Radar Topography Mission (SRTM), resolução espacial de 30 m, para gerar o MDE e os mapas morfométricos de: Declividade, Orientação de vertentes (aspecto), Hipsometria, Curvatura Vertical e Curvatura Horizontal. A declividade consiste no ângulo de inclinação da superfície do terreno em relação ao plano horizontal, distingue as áreas planas de relevos mais acidentados. A hipsometria representa a elevação do terreno. A curvatura vertical (profile curvature) representa o caráter côncavo/convexo do perfil do terreno. A curvatura horizontal (plan curvature) corresponde ao caráter divergente/convergente das linhas de fluxo (MACHADO, 2014). Foram utilizados os softwares Quantum Gis e ArcGis licenciado pela UFRGS, para extrair os valores dos dados morfométricos em relação aos pontos de ruptura (coroa). Os pontos foram classificados em clusters, agrupando as feições de acordo com suas características.

Foram utilizados algoritmos de aprendizado de máquina, avaliados diversos parâmetros a partir do algoritmo K-means e verificado se os resultados cumprem satisfatoriamente os objetivos propostos. O Kmeans é amplamente utilizado para solucionar problemas de agrupamento devido à sua eficiência e implementação simples. Esse algoritmo agrupa um determinado conjunto de dados em clusters, nos quais cada valor de atributo é atribuído ao centróide mais próximo. O valor do centróide do cluster é obtido da média dos valores dos atributos (WANG, 2017).

Utilizando o K-means foram: 1) Atribuídos valores iniciais para os protótipos seguindo critérios como, por exemplo, sorteio aleatório dos valores dentro dos limites de domínio de cada atributo; 2) Atribuído cada objeto ao grupo cujo protótipo possuísse maior similaridade com o objeto; 3) Recalculado o valor do centróide (protótipo) de cada grupo, como sendo a média dos objetos atuais do grupo; 4) Repetidos os passos 2 e 3, até que os grupos se estabilizassem. Foi considerado o número de classes de 2 até 10, totalizando 9 mapas de clusterização, denominados a partir daqui como: Cluster-2, Cluster-3, Cluster-4, Cluster-5, Cluster6, Cluster-7, Cluster-8, Cluster-9 e Cluster-10 (CONRAD et al., 2015). Foi utilizado o SAGA-GIS para o método de clusterização.

Por fim, foram elaborados perfis topográficos de vertentes, identificados e localizados os pontos de ruptura de deslizamentos nas vertentes. Buscou-se identificar a relação entre o formato da vertente e o local da ocorrência do ponto de ruptura. Foram utilizadas duas escalas de análise, uma escala menor considerando a abrangência de toda a bacia hidrográfica, e outra, uma escala de detalhe para analisar apenas o perfil das vertentes.

\section{Resultados}

A partir do inventário e mapeamento foram selecionados os 143 pontos de ruptura classificados como cicatrizes relacionadas a deslizamentos. Essa classificação permitiu padronizar as condições morfométricas em relação à gênese da sua ocorrência. A partir do modelo digital de elevação foram obtidos dados geomorfométricos, que foram correlacionados com os pontos de ruptura (coroa) de deslizamentos.

Os perfis de vertente (Figura 6) mostram 4 tipos de vertentes identificadas na bacia do rio Rolante. Os perfis côncavos e convergentes apresentaram a menor ocorrência, e os perfis convexos e divergentes apresentaram o maior número de ocorrências na bacia. A análise a partir dos perfis mostra que a localização dos pontos de ruptura nas vertentes ocorre na Unidade 3, conforme modelo de vertentes de Dalrymple et al. (1968). Essa localização é predominante, e ocorre em mais de 70\% das amostras de deslizamentos na bacia.

Em relação à declividade, foram identificados 13 pontos de ruptura na classe entre $10^{\circ}$ e $20^{\circ} ; 45$ entre $20^{\circ}$ e $30^{\circ}$ e 85 ocorrências na classe maior que $30^{\circ}$. Em declividades inferiores a $10^{\circ}$ não foram identificados pontos de ruptura de deslizamento (Tabela 1).

Em relação à elevação, a maior concentração de pontos de ruptura ocorreu entre 500 e 800 m. Foram 31 pontos entre 500 e $600 \mathrm{~m}, 49$ pontos entre 600 e $700 \mathrm{~m}$ e 28 pontos entre 700 e $800 \mathrm{~m}$. Não apresentando correlação significativa entre a elevação e os pontos de ruptura (Tabela 2). 

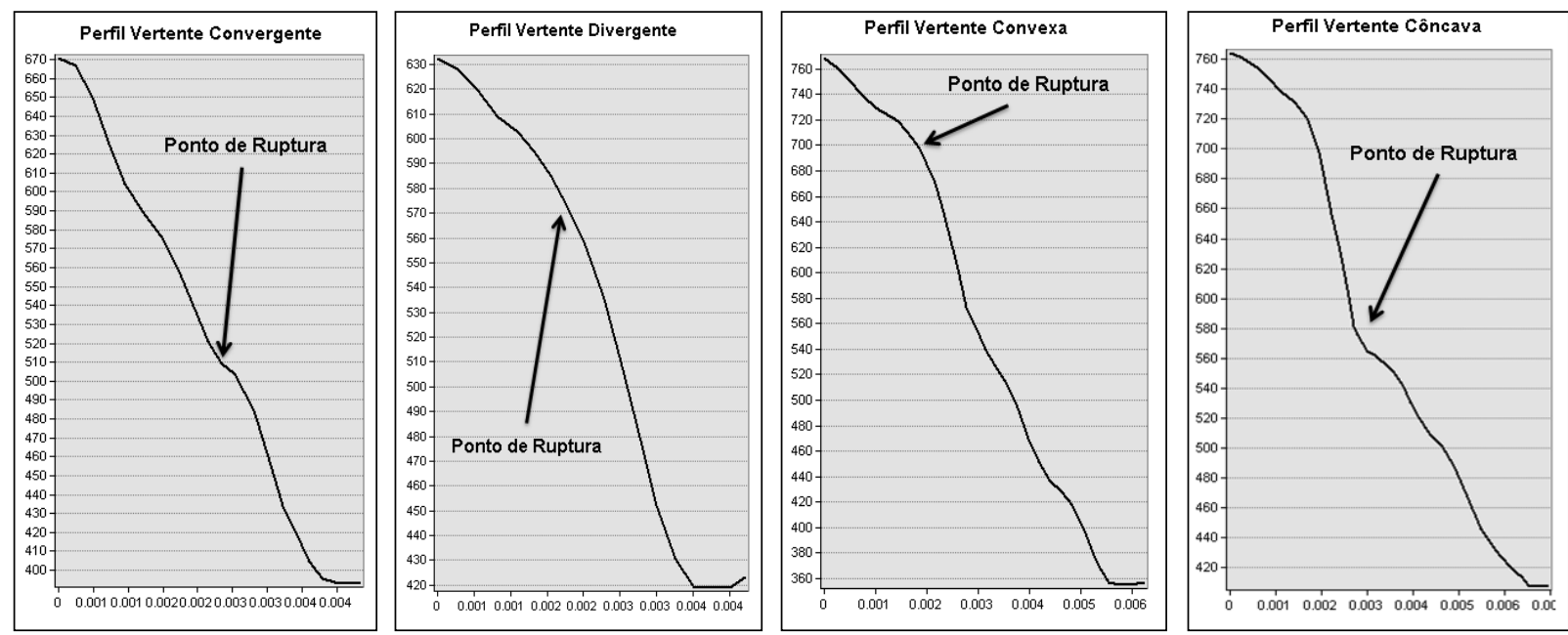

Figura 6. Perfil de vertente com ponto de ruptura localizado em perfil convergente (A); divergente (B); em perfil de vertente convexa (C); e côncava (D).

Tabela 1: Relação entre declividades e ocorrências de pontos de ruptura

\begin{tabular}{cccc}
\hline Declividade $\left(^{\mathbf{}}\right.$ ) & Ocorrências & Declividade $\left(^{\mathbf{}}\right.$ ) & Ocorrências \\
\hline $0-5$ & - & $20-30$ & 45 \\
$5-10$ & - & $>30$ & 85 \\
$10-20$ & 13 & Total & 143 \\
\hline
\end{tabular}

Tabela 2: Relação entre elevação e ocorrências de pontos de ruptura

\begin{tabular}{cccccc}
\hline Classes & Elevação & Ocorrências & Classes & Elevação & Ocorrências \\
\hline 1 & $12-100$ & - & 6 & $500-600$ & 31 \\
2 & $100-200$ & - & 7 & $600-700$ & 49 \\
3 & $200-300$ & - & 8 & $700-800$ & 28 \\
4 & $300-400$ & 2 & 9 & $800-900$ & 19 \\
5 & $400-500$ & 12 & 10 & $900-992$ & 2 \\
\hline
\end{tabular}

A orientação de vertentes também não apresentou correlação. Os pontos de ruptura estão distribuídos em todos os intervalos de orientação. As maiores ocorrências foram no setor noroeste, nordeste e sudoeste com 27,22 e 20 pontos de ruptura, respectivamente.

Quanto à curvatura plana, os pontos de ruptura se localizam na sua maioria em vertentes do tipo divergentes, com 91 ocorrências (63\%), e nas convergentes com 52 ocorrências (37\%). A curvatura vertical apresentou $102(71 \%)$ pontos de ruptura em vertentes do tipo convexo, e vertentes côncavas corresponderam a 41 pontos $(29 \%)$. Ocorreu maior relação entre as vertentes com padrão convexo e divergente em relação a localização dos pontos de ruptura nas vertentes (Tabela 3).

Tabela 3: Relação entre curvaturas e ocorrências de pontos de ruptura

\begin{tabular}{cccc}
\hline Curvatura Vertical & Ocorrências & Curvatura Plana & Ocorrências \\
\hline Côncavo & 41 & Convergentes & 52 \\
Convexo & 102 & Divergentes & 91 \\
\hline
\end{tabular}

Nos mapas gerados a partir de agrupamentos K-means, os Cluster 2, 3, 8, 9 e 10 não apresentaram correlação entre os atributos. Os valores médios apresentados em cada centroide estão distantes, sem valores médios próximos. Os mapas de Clusters 4,5 e 6 foram mais representativos em relação à divisão de atributos. Os valores médios das classes estão mais próximos uns dos outros, principalmente os valores das curvaturas e as declividades (Tabelas 4 e 5 ).

Os agrupamentos cluster 4, 5 e 6 apresentaram resultados semelhantes com médias próximas (Tabela 5). Dividiram os mesmos pontos de ruptura em 3 clusters principais, cluster 2 com 15 pontos, cluster 3 com 98 pontos e cluster 4 com 30 pontos. Os demais clusters em cada agrupamento não apresentaram pontos de ruptura. 
Tabela 4: Agrupamento k-means clusters 2 e 3 e quantidade de pontos de ruptura em cada cluster

\begin{tabular}{cccc}
\hline Cluster-2 & Pontos & Cluster-3 & Pontos \\
\hline Cluster 1 & 35 & Cluster 1 & 0 \\
Cluster 2 & 108 & Cluster 2 & 90 \\
- & - & Cluster 3 & 53 \\
\hline
\end{tabular}

A declividade apresentou média acima de $30^{\circ}$ em todos os agrupamentos. $\mathrm{O}$ cluster 1 não apresentou pontos de ruptura, o cluster 2 teve média de $32,26^{\circ}$, o cluster 3 teve média de $31,34^{\circ}$, e o cluster 4 a média foi de $31,10^{\circ}$. As médias das declividades apresentaram valores próximos em cada um dos clusters, o que pode identificar um fator comum entre as ocorrências.

A elevação apresentou o primeiro cluster com média de 462,26 m, o segundo cluster com $640,28 \mathrm{~m}$ e o terceiro com $826,82 \mathrm{~m}$. O segundo cluster apresentou o maior número de pontos de ruptura, com 98 pontos e média de 640,28 m.

Tabela 5: Agrupamento K-means clusters 4, 5 e 6, quantidade de pontos de ruptura em cada cluster, e valores médios para declividade, elevação e curvaturas (Curvatura Média Horizontal e Curvatura Média Vertical)

\begin{tabular}{lccccc}
\hline Cluster-4, 5, 6 & Pontos & Declividade Média & Elevação Média & Curv Média Horizontal & Curv Média Vertical \\
\hline Cluster 1 & 0 & - & - & - & - \\
Cluster 2 & 15 & $32,26^{\circ}$ & $462,26 \mathrm{~m}$ & Divergente & Côncavo \\
Cluster 3 & 98 & $31,34^{\circ}$ & $640,28 \mathrm{~m}$ & Divergente & Convexo \\
Cluster 4 & 30 & $31,10^{\circ}$ & $826,82 \mathrm{~m}$ & Divergente & Convexo \\
\hline
\end{tabular}

Nos perfis de vertentes, as elevações onde ocorrem os pontos de ruptura possuem valores variados, sem correlação com as amostras. Em relação à curvatura plana, todos os clusters apresentaram pontos médios com curvatura divergente. Em relação à curvatura vertical, o cluster com 15 pontos apresentou curvatura vertical côncava. Os outros 2 clusters apresentaram curvatura convexa, um cluster com 98 e outro com 30 pontos de ruptura. O cluster com curvatura côncava foi o agrupamento com menos ocorrências, o que demonstra uma correlação entre os pontos de ruptura de deslizamentos e as vertentes divergentes e convexas.

A distribuição de classes a partir do agrupamento de 4 clusters, (Figura 7), se mostrou mais bem representado na distribuição, com menor confusão. É possível observar a separação entre curvatura vertical (CPRF) e curvaturas planas (CPLN).

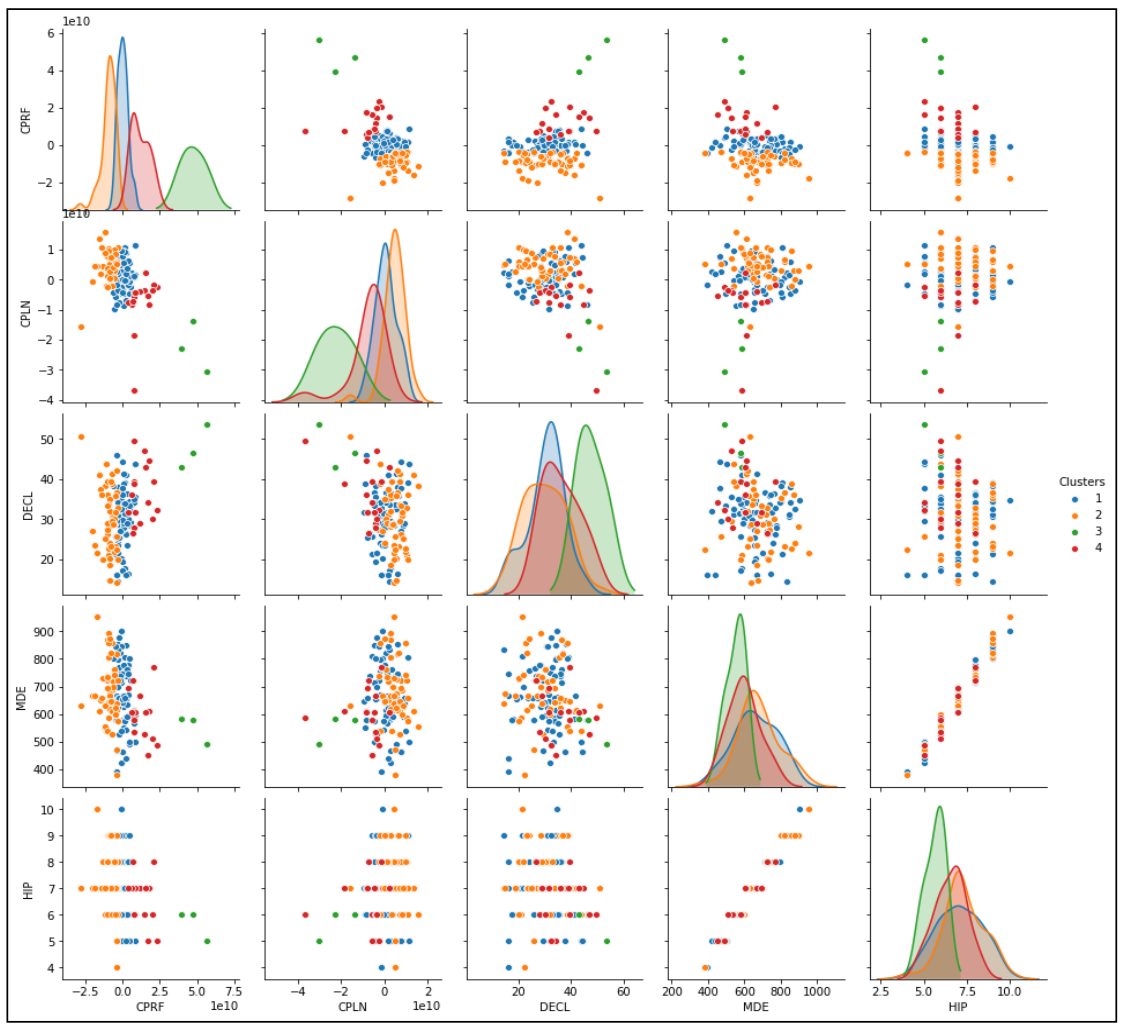

Figura 7. Distribuição de classes a partir do agrupamento em 4 clusters 
As curvaturas verticais (CPRF) e as curvaturas planas (CPLN) apresentam pontos separados entre as 4 classes. É perceptível nos gráficos que cada cluster corresponde a um pico no gráfico em relação às duas curvaturas, e indica que ocorreu menor confusão. Em relação às declividades (DECL) ocorreu maior confusão em relação à divisão dos clusters, mas ainda se identifica uma distinção entre os clusters 1 e 3 . Quanto ao modelo digital de elevação (MDE) e o mapa hipsométrico (HIP) ocorreu maior confusão na distribuição, devido à dificuldade em agrupar os pontos em classes iguais, visto que a elevação não apresenta grande relação com os pontos de ruptura trabalhados.

O agrupamento cluster 7 apresentou 4 clusters com pontos de ruptura, sendo que os clusters 1,6 e 7 não apresentaram pontos agrupados. As médias de declividade e elevação apresentaram valores distintos (Tabela 6). Para a curvatura plana, 3 clusters apresentaram média divergente, com exceção do primeiro cluster que apresentou média convergente, apenas 4 pontos de ocorrência foram agrupados nesse ponto de ruptura. Quanto às curvaturas verticais, todos os clusters apresentaram perfil convexo.

Tabela 6: Agrupamento K-means para 7 cluster, quantidade de pontos de ruptura em cada cluster, e valoresmédios para declividade, elevação e curvaturas (Curvatura Média Horizontal e Curvatura Média Vertical)

\begin{tabular}{cccccc}
\hline Cluster-7 & Pontos & $\begin{array}{c}\text { Declividade } \\
\text { Média }\end{array}$ & $\begin{array}{c}\text { Elevação } \\
\text { Média }\end{array}$ & $\begin{array}{c}\text { Curv Média } \\
\text { Horizontal }\end{array}$ & $\begin{array}{c}\text { Curv Média } \\
\text { Vertical }\end{array}$ \\
\hline Cluster 1 & 0 & - & - & - & - \\
Cluster 2 & 4 & $21,66^{\circ}$ & 408,5 & Convergente & Convexo \\
Cluster 3 & 61 & $34,47^{\circ}$ & 569,90 & Divergente & Convexo \\
Cluster 4 & 62 & $29,13^{\circ}$ & 713,09 & Divergente & Convexo \\
Cluster 5 & 16 & $30,71^{\circ}$ & 860,75 & Divergente & Convexo \\
Cluster 6 & 0 & - & - & - & - \\
Cluster 7 & 0 & - & - & - & - \\
\hline
\end{tabular}

\section{Discussões}

A relação entre padrões morfométricos e pontos de ruptura (coroa) de deslizamentos a partir de agrupamento K-means, mostrou que com base nas médias dos principais agrupamentos de clusters, a declividade e as curvaturas tiveram a maior importância em relação a localização dos pontos de ruptura na vertente, e são importantes como condicionantes de suscetibilidade aos deslizamentos. As médias dos agrupamentos de todos os clusters ocorreram acima de $30^{\circ}$ de declividade no agrupamento com 4 clusters, que foi mais representativo.

Ao analisar o efeito de diferentes graus de declividade mais utilizados na literatura sobre a ocorrência de deslizamentos, Çellek (2020) destaca que apesar de muitos pesquisadores afirmarem que com o aumento da declividade aumenta a suscetibilidade a deslizamentos, para outros os deslizamentos também podem ocorrer em ângulos de inclinação mais baixa. Entretanto, é consenso que os deslizamentos aumentam com o valor da inclinação, mas que deslizamentos são raros se estiverem acima de $30^{\circ}$, e que, com base na literatura analisada, deslizamento acima de $45^{\circ}$ não são encontrados.

Entretanto, segundo Danelon e Pedrosa (2004) a declividade teve maior importância para explicar o desencadeamento de movimentos de massa com declives entre $18^{\circ}$ e $45^{\circ}$. E para Dias et al. (2017) valores semelhantes em deslizamentos ocorrem em encostas com inclinação $>30^{\circ}$ e vertentes côncavas.

É importante destacar também, que evento atípicos de precipitação extrema como o ocorrido na região podem deflagrar deslizamentos em declividades nos quais precipitações normais não o fariam, ocasionando deslizamentos por saturação do solo com posterior quebra de coesão, fato esse que pode explicar a magnitude da ocorrência dos deslizamentos na região no referido período, além de algumas ocorrências em áreas de declividades baixas com média de 21,66 , como foi identificado no agrupamento de Cluster-7.

Destaca-se nesse trabalho a importância do uso de um inventário de áreas de ocorrência de deslizamentos, o que permitiu identificar a localização de cada ocorrência de deslizamento, e a sua magnitude. Diversos autores destacam a importância das variáveis morfométricas para o estudo de deslizamentos, considerando de suma importância ampliar os bancos de dados para melhorar as análises quantitativas na identificação de 
áreas suscetíveis a deslizamentos (WOODCOCK, 1979; MACDONALD et al., 1993; HAFLIDASON et al., 2005, MASCARDELLI; WOOD, 2015).

No modelo de vertente proposto por Dalrymple et al. (1968) os deslizamentos geralmente ocorrem a partir da Unidade de Vertente 4, e os processos de rastejos na Unidade 3. Entretanto, o que se observou na maioria dos perfis de vertente extraídos na bacia de estudo (Figuras 3 a 6), é que os pontos de ruptura de deslizamentos, sem intervenção antrópica, geralmente estão localizados na Unidade de Vertente 4. Para alguns autores os processos de rastejo são um indício da ocorrência de deslizamentos (AUGUSTO FILHO, 1995; INFANTI Jr.; FORNASARI FILHO, 1998; HIGHLAND; BOBROWSKY, 2008).

A maioria dos pontos de ruptura (coroa) ocorreu em vertentes convexas e divergentes. Entretanto, segundo a literatura (FERNANDES; AMARAL, 1996; HAMPTON et al., 1996; HÜHNERBACH; MASSON, 2004; FONSECA, 2010), as vertentes côncavas e convergentes são acumuladoras de água e, portanto, mais suscetíveis a deslizamentos. Para esses autores, as vertentes que apresentam configuração côncava ou que possuem segmentos côncavos em sua seção (hollows) por serem zonas de convergência de fluxo de água, e possuírem material disponível para a mobilização, são as mais suscetíveis a deslizamentos.

No entanto, segundo Christofoletti (1974) sob clima úmido, muitas rochas geram morros de vertentes dominantemente convexas. Locais onde se encontram formas mais verticalizadas, como espigões e serras, apresentam-se escarpadas, com elevadas altitudes, vertentes longas e altas declividades. A intensa pluviosidade nestas áreas faz com que estes tipos de terreno sejam suscetíveis a deslizamentos.

Índices extremos de precipitação explicam também o elevado número de deslizamentos ocorridos em curto intervalo de tempo na região da bacia do rio Rolante. No entanto, devido à falta de pluviômetros, não foi possível obter dados qualificados sobre os totais de precipitação. Diversos autores (FULLEN, 2003; CROZIER; GLADE, 2005; KANUNGO; SHARMA, 2014; ARBUCKLE et al., 2015; AGNIHOTRI; KUMAR, 2015) citam as precipitações extremas como eventos importantes nas ocorrências de deslizamentos.

O método K-means permitiu agrupar os diversos dados morfométricos de várias ocorrências de deslizamentos. Com a vantagem de ser um método eficiente e de implementação simples foi possível identificar os padrões geomorfológicos de maior relação com os pontos de ruptura em deslizamentos na bacia hidrográfica em análise.

Diversos autores tem utilizado o método K-means para analisar dados morfométricos relacionados a deslizamentos, entre eles destacamos o trabalho de Wang et al. (2017) em que utilizaram o algoritmo Kmeans para identificar combinações ideais de fatores causais de deslizamentos, e concluíram que os fatores área de captação e distância à cicatriz tiveram as menores consistências como coeficientes de informação, permitindo obter mapas de suscetibilidade a deslizamentos mais precisos usando os fatores causais.

Pokharel et al. (2020) testaram estratégias alternativas de amostragem com base em conceitos de distribuição de agrupamento para aumentar a eficiência dos resultados do modelo de suscetibilidade a deslizamentos, em vez do método de seleção aleatória comum para treinamento e teste de amostras. Utilizaram um inventário de deslizamento e seis algoritmos de agrupamento não supervisionados (K-médias, K-medoides, análise de agrupamento hierárquico (HC), expectativa-maximização usando modelos de mistura gaussiana (EM / GMM), propagação de afinidade e mini batch K-means) e geraram seis conjuntos de dados de treinamento diferentes.

Ressalta-se dessa forma, que o método K-means tem apresentado boas respostas para diversas metodologias empregadas no mapeamento de deslizamentos, pois ao agrupar conjuntos de dados sobre deslizamentos, as características médias das ocorrências de uma determinada região podem ser descritas de uma forma mais eficiente.

Salienta-se que todas as ocorrências mapeadas neste trabalho ocorreram em áreas de terrenos naturais, sem intervenções antrópicas, visto que muitas vezes a ação humana pode ser um agente deflagrador que pode induzir deslizamentos em diferentes perfis e declividades, devido à ações como cortes, aterros, alterações na vegetação entre outros fatores.

\section{Conclusões}

Os resultados mostraram que os pontos de ruptura de deslizamentos na bacia do rio Rolante têm padrões que podem ser relacionados e classificados segundo parâmetros geomorfológicos. A maioria dos pontos de ruptura de deslizamentos ocorreu em vertentes convexas e divergentes e com altas declividades. 
A declividade teve um importante papel no desencadeamento dos deslizamentos, visto que a maioria dos pontos está em vertentes com inclinação superior a $30^{\circ}$. A elevação e a orientação de vertentes, no entanto, não apresentaram relação com os pontos de ruptura.

A metodologia permitiu agrupar os pontos de ruptura de deslizamentos de acordo com os padrões geomorfométricos com maior repetição em cada cluster.

Os resultados foram identificados a partir de duas escalas de análise. Uma escala abrangeu toda a bacia e identificou as características geomorfológicas que mais se relacionavam com os pontos de ruptura. Numa segunda escala, de mais detalhe, foram elaborados perfis topográficos, e sua relação com os pontos de ruptura e as características da vertente, como as curvaturas de vertente e as declividades.

É importante ressaltar que cada bacia hidrográfica possui características únicas. Da mesma forma, eventos de ocorrência de deslizamentos possuem características distintas relacionadas a precipitação e ao tipo e espessura do solo e podem também trazer resultados diferentes. Por isso é importante analisar as particularidades de cada área de estudo.

\section{Referências}

AGNIHOTRI, P.; KUMAR, A. Greenhouse gas emissions and climate change: Options to mitigate climate change. Am J Pharm Health Res. V.3, 54-59, 2015.

ALI, R.; KURIQI, A.; OZGUR KISI, O. Human-Environment Natural Disasters Interconnection in China: A Review. Climate, v. 8, n. 48, 2020. https://doi.org/10.3390/cli8040048

MATYA, P.; KIRSCHBAUM, D.; THOMAS STANLEY, T. Use of Very High-Resolution Optical Data for Landslide Mapping and Susceptibility Analysis along the Karnali Highway, Nepal. Remote Sens., v. 11, 2284, 2019. doi:10.3390/rs11192284.

ARBUCKLE, J. G.; MORTON, L. W.; HOBBS, J. Understanding farmer perspectives on climate change adaptation and mitigation: The roles of trust in sources of climate information, climate change beliefs, and perceived risk. Environ Beha v. 47, p. 205-234, 2015. https://doi.org/10.1177\%2F0013916513503832

ASSOCIAÇÃO BRASILEIRA DE NORMAS TÉCNICAS (ABNT). NBR 11.682: 2009. Estabilidade de encostas. Rio de Janeiro, 38 p. 2009.

AUGUSTO FILHO, O. Escorregamentos em encostas naturais e ocupadas: análise e controle. In: BITAR, O.Y. (Coord.). Curso de geologia aplicada ao meio ambiente. São Paulo: Associação Brasileira de Geologia de Engenharia (ABGE) e Instituto de Pesquisas Tecnológicas (IPT), cap. 3.4, p.77-100, 1995.

ARMAŞ, I. Weights of evidence method for landslide susceptibility mapping. Prahova Subcarpathians, Romania. Nat Hazards, v.60, p.937-950, 2012. https://doi.org/10.1007/s11069-011-9879-4.

AYALEW L.; YAMAGISHI H. The application of GIS-based logistic regression for landslide susceptibility mapping in the Kakuda Yahiko mountais, central Japan. Geomorphology v. 65, p. 15-31, 2005. http://dx.doi.org/10.1016/j.geomorph.2004.06.010

AVANZI, G.D.; GIANNECHINI, R.; PUCCINELLI, A. The influence of the geological and geomorphological settings on shallow landslides. An example in a temperate climate environment: the June 19, 1996 event in northwestern Tuscany (Italy) Engineering Geology, v. 73, p. 215-228, 2004.

ÇELLEK, S. Effect of the Slope Angle and Its Classification on Landslide. Preprint. Discussion started: 8 May 2020. https://doi.org/10.5194/nhess-2020-87

CERRI, R. I. et al. Landslides Zonation Hazard: relation between geological structures and landslides occurrence in hilly tropical regions of Brazil. An. Acad. Bras. Ciênc. [online]. v.89, n.4, p.2609-2623, 2017. ISSN 1678-2690. http://dx.doi.org/10.1590/0001-3765201720170224. 
CHANG, K.; CHAN, Y.; CHEN, R.; HSIEH, Y. Geomorphological evolution of landslides near an active normal fault in northern Taiwan, as revealed by lidar and unmanned aircraft system data. Nat. Hazards Earth Syst. Sci., v.18, p.709-727, 2018. https://doi.org/10.5194/nhess-18-709-2018

CONRAD, O.; BECHTEL, B.; BOCK, M.; DIETRICH, H.; FISCHER, E.; GERLITZ, L.; WEHBERG, J.; WICHMANN, V.; and BÖHNER, J. System for Automated Geoscientific Analyses (SAGA) v. 2.1.4, Geosci. Model De. v., 8, p. 1991-2007, 2015. doi:10.5194/gmd-8-1991-2015.

CONSTANTIN, M., BEDNARIK, M., JURCHESCU, M. C. et al. Landslide susceptibility assessment using the bivariate statistical analysis and the index of entropy in the Sibiciu Basin (Romania). Environ Earth Sci, v.63, p.397-406, 2011. https://doi.org/10.1007/s12665-010-0724-y

COSTA NUNES, A. J. Engenharia Geotécnica, o Legado de A. J. da Costa Nunes. Tecnosolo. p.253-252, Rio de Janeiro, 1992.

CPRM - Serviço Geológico do Brasil. Mapa Geológico do Estado do Rio Grande do Sul, escala 1:750.000. 2009 .

CROZIER M. J.; GLADE T. Landslides hazard and risk: issues, concepts and approach. In Glade T, Anderson M, Crozier M (eds.) Landslide Hazard and Risk. John Wiley, New York. p. 141, 2005.

DAMAYANTI, A.; ANGIN, F.; ADIB, A.; IRFAN, M. Geomorphological Characteristic of Landslide Hazard Zones in Sukarame Village, Cisolok Subdistric, Sukabumi Regency. 2nd International Conference on Geography and Education. IOP Conf. Series: Earth and Environmental Science, 412, 2020.

DIAS, H. C.; DIAS, V. C.; VIEIRA, B. C. Condicionantes Morfológicos e Geológicos dos Escorregamentos Rasos na Bacia do Rio Santo Antônio, Caraguatatuba/SP. Revista do Departamento de Geografia da USP, Volume Especial - XVII SBGFA / I CNGF, 2017. https://doi.org/10.11606/rdg.v0ispe.132714

DING, C.; HE, X. K-means clustering via principal component analysis. In Proceedings of the Twenty-First International Conference on Machine Learning, Banff, AB, Canada, 4-8, 2004.

DOMEJ, G.; BOURDEAU, C.; LENTI, L.; MARTINO, S.; PLUTA, K. Shape and Dimension Estimations of Landslide Rupture Zones via Correlations of Characteristic Parameters. Geosciences. v. 10, p.198, 2020. https://doi.org/10.3390/geosciences 10050198

ERENER, A.; DÜZGÜN, H.S.B. Landslide susceptibility assessment: what are the effects of mapping unit and mapping method? Environ Earth Sci, v. 66, p. 859-877, 2012. http://dx.doi.org/10.1007/s12665-011$1297-0$

FERNANDES, N. F.; AMARAL, C. P. Movimentos de massa: uma abordagem geológico geomorfológica. In Guerra, A.J.T. e Cunha, S.B. (org.) Geomorfologia e Meio Ambiente. Bertrand, Rio de Janeiro: p. 123194, 1996.

FERNANDES, N. F.; GUIMARÃES, R. F.; GOMES, R. A. T.; VIEIRA, B. C.; MONTGOMERY, D. R.; GREENBERG, H. Condicionantes Geomorfológicos dos Deslizamentos nas Encostas: Avaliação de Metodologias e Aplicação de Modelo de Previsão de Áreas Susceptíveis. Revista Brasileira de Geomorfologia, v. 2, n.1, p.51-71, 2001. http://dx.doi.org/10.20502/rbg.v2i1.8

FONSECA, I. L. Modelação de formas de relevo para aplicação à cartografia de solos. Anais do V Congresso Nacional de Geomorfologia. Porto, 2010.

FROUDE, M. J.; PETLEY, D. N. Global fatal landslide occurrence from 2004 to 2016. Nat. Hazards Earth Syst. Sci., v.18, p. 2161-2181, 2018. https://doi.org/10.5194/nhess-18-2161-2018

FULlen, M. A. Soil erosion and conservation in northern Europe. Prog Phys Geog. v. 27, p.331-358. 2003. 
GAMEIRO, S.; QUEVEDO, R. P.; OLIVEIRA, G. G.; RUIZ, L. C.; GUASSELli, L. A. Análise e Correlação de Atributos Morfométricos e sua Influência nos Movimentos de Massa Ocorridos na Bacia do Rio Rolante, RS. Anais... XIX Simpósio Brasileiro de Sensoriamento Remoto, Santos-SP. 2019

GARIANO, S. L.; GUZZETTI, F. Landslides in a changing climate. Earth-Science Reviews v.162, p.227252, 2016. https://doi.org/10.1016/j.earscirev.2016.08.011

GUERRA, J. T.; BEZERRA, J. F. R.; FULLEN, M. A.; MENDONÇA, J. K. S.; JORGE, M. C. O. The effects of biological geotextiles on gully stabilization in São Luís, Brazil. Nat Hazards. V. 75, p. 2625-2636, 2015. http://dx.doi.org/10.1007/s11069-015-1878-4

GUERRA, A. J. T. The effect of organic matter content on soil erosion in simulated rainfall experiments in W. Sussex, UK. Soil Use Manage. V. 10, p. 60-64, 1994. http://dx.doi.org/10.1111/j.14752743.1994.tb00460.x

GUIDICINI, G.; NIEBLE, C. M. Estabilidade de taludes naturais e de escavação. Edgard Blücher, São Paulo, 1984.

GUZZETTI, F.; REICHENBACH, P.; CARDINALI, M.; GALLI.; ARDIZZONE, F. Probabilistic landslide hazard assessment at the basin scale. Geomorphology, v. 72, p.272-299, 2005. http://dx.doi.org/10.1016/j.geomorph.2005.06.002

GUZZETTI, F.; MONDINI, A. C.; CARDINALI, M.; FIORUCCI, F.; SANTANGELO, M.; CHANG, K. Landslide inventory maps: New tools for an old problem. Earth-Science Reviews, v. 112, p. 42-66, 2012.

HAFLIDASON, H.; LIEN, R.; SEJRUP, H.P.; FORSBERG, C.F.; BRYN, P. The dating and morphometry of the Storegga Slide: Marine and Petroleum Geology, v. 22, p. 123-136, 2005. http://dx.doi.org/10.1016/j.marpetgeo.2004.10.008

HAMPTON, M.A.; LEE, H.J.; LOCAT, J. Submarine landslides: Reviews of Geophysics, v. 34, p. 33-59, 1996.

HARIST, M. C.; AFUIF, H. A.; PUTRI, D. N.; SHIDIQ, I. P. A. GIS modelling based on slope and morphology for landslide potential area in Wonosobo, Central Java. MATEC Web of Conferences 229, 03004, 2018.

HEARN, G. J. Terrain hazard mapping at Ok Tedi mine, Papua New Guinea. 6th International Symp. on Landslides, A. A. Balkema, Christchurch: 971-976, 1992.

HIGHLAND, L. M.; BOBROWSKY, P. The landslide handbook - A guide to understanding landslides: Reston, Virginia, U.S. Geological Survey Circular 1325, 129p, 2008.

HONG, Y.; ADLER, R. F.; HUFFMAN, G. An experimental global prediction system for rainfall-triggered landslides using satellite remote sensing and geospatial datasets. IEEE. Trans Geosci Remote Sens v. 45(6), p. 1671-1680, 2007. http://dx.doi.org/10.1109/TGRS.2006.888436

HÜHNERBACH, V.; MASSON, D. G. Landslides in the North Atlantic and its adjacent seas: An analysis of their morphology, setting and behaviour: Marine Geology, v. 213, p. 343-362, 2004.

HUNGR, S. G.; EVANS, S. G.; BOVIS, M. J.; HUTCHINSON, J. N. A review of the classification of landslides of the flow type. Environmental \& Engineering Geoscience, v. 3, n. 3, p. 221-238, 2001. http://dx.doi.org/10.2113/gseegeosci.7.3.221

INFANTI JUNIOR, N.; FORNASARI FILHO, N. Processos de Dinâmica Superficial. In: OLIVEIRA, A.M.S. \& BRITO, S.N.A. (Eds.). Geologia de Engenharia. São Paulo: Associação Brasileira de Geologia de Engenharia (ABGE), cap. 9, p.131-152, 1998. 
IVANOV, V.; AROSIO, D.; TRESOLDI, G.; HOJAT, A.; ZANZI, L.; PAPINI, M.; LANGONI, L. Investigation on the Role of Water for the Stability of Shallow Landslides-Insights from Experimental Tests. Water, v. 12, 1203 p., 2020. doi:10.3390/w12041203

KAMP, U.; GROWLEY, B.J.; KHATTAK, G.A.; OWEN, L.A. GIS-based landslide susceptibility mapping for the 2005 kashmir earthquake region. Geomorphology, v. 101, p. 631-642, 2008. http://dx.doi.org/10.1016/j.geomorph.2008.03.003

KANUNGO, T.; MOUNT, D. M.; NETANYAHU, N. S., PIATKO, C. D.; SILVERMAN, R.; WU, A. Y. An efficient k-means clustering algorithm: analysis and implementation, in IEEE Transactions on Pattern Analysis and Machine Intelligence, v. 24, no. 7, p. 881-892, 2002. http://dx.doi.org/10.1109/TPAMI.2002.1017616

KIRKBY, M. J. Hillslope runoff processes and models, Journal of Hydrology, v. 111, p. 315-339, 1988.

LACASSE, S.; NADIM, F.; KALSNES, B. Living with Landslide Risk. Geotechnical Engineering Journal of the SEAGS \& AGSSEA, v. 41, n. 4, 2010.

LARA, A. A.; MARQUES, E. A. G.; ALMEIDA, L. C. R. Mapeamento de risco de acidentes associados a escorregamentos - Morro da Serrinha, Rio de Janeiro, Brasil. $2^{\text {a }}$ COBRAE. ABMS, ABGE e ISSMGE, Rio de Janeiro: 837-845, 1997.

LEE, CHYI-TYI. Landslide trends under extreme climate events. Terr. Atmos. Ocean. Sci., v. 28, n. 1, p.3342, 2017. http://dx.doi.org/10.3319/TAO.2016.05.28.01

LEE, S.; CHOI, J. The effect of spatial resolution on the accuracy of landslide susceptibility mapping: A case study in Boun, Korea. Geosciences Journal, v. 8, n. 1, p. 51-60, 2004. DOI: 10.1007/BF02910278.

LIN, Y. P.; CHUL, H. J.; WU, C. F. Spatial pattern analysis of landslide using landscape metrics and logistic regression: a case study in Central Taiwan. Hydrol. Earth Syst. Sci. Discuss., v.7, p.3423-3451, 2010.

LIKAS, A.; VLASSIS, N.; VERBEEK, J. J. The global K-means clustering algorithm. Pattern Recogn. V. 36, p. 451-461, 2003. http://dx.doi.org/10.1016/S0031-3203(02)00060-2

LUERCE, T. D. Geoturismo na bacia hidrográfica do rio Rolante-RS: Um estudo acerca das Quedas d’água. Porto Alegre. Dissertação de Mestrado, Programa de Pós-Graduação em Geografia, Universidade Federal do Rio Grande do Sul, 2015.

LUERCE, T. D.; OLIVEIRA, G. G.; GUASSELli, L. A.; BRUBACHER, J. P. Mapeamento geomorfológico a partir de dados SRTM: bacia hidrográfica do rio dos Sinos, RS. Simpósio Brasileiro de Sensoriamento Remoto - SBSR, Foz do Iguaçú, INPE, p.1863-1870, 2013. ISBN: 978-85-17-00057-7.

MACDONALD, D. I. M.; MONCRIEFF, A. C. M.; BUTTERWORTH, P. J. Giant slide deposits from a Mesozoic forearc basin, Alexander Island, Antarctica: Geology, v. 21, p. 1047-1050, 1993.

MACHADO, A. S. V. Geomorfometria da Região da Fartura (SP). Rio Claro, SP. São Paulo. Dissertação de Mestrado, Programa de Pós-Graduação em Geociências e Meio Ambiente, Universidade Estadual Paulista, 2014.

MACHADO, L. A. Classificação climática para minas gerais por meio do método de agrupamento não hierárquico de k-means. Cadernos do LESTE, v. 14, n. 14, 2014.

MARANGON, M. Estabilidade de taludes. Tópicos em Geotecnia e Obras de Terra. UFJF, 2009. Disponivel em: < http://www.ufjf.br/nugeo/files/2009/11/togot_Unid04EstabilidadeTaludes01.pdf> Acesso em: 16 jun. 2020.

MOORE, I. D.; GRAYSON, R. B.; LADSON, A. R. Digital terrain modeling: a review of hydrological, geomorphological and biological applications. Hydrol Process v. 5, p.3-30, 1991. 
NADIM, F.; KJEKSTAD, O.; PEDUZZI, P.; HEROLD, C.; JAEDICKE C. Global landslide and avalanche hotspots. Landslides v. 3(2), p. 159-173, 2006.

OHLMACHER, G. C.; DAVIS J. C. Using multiple logistic regression and GIS technology to predict landslide hazard in northeast Kansas, USA. Eng Geol v. 69, p. 331-343, 2003. http://dx.doi.org/10.1016/S0013-7952(03)00069-3

OLIVEIRA, G.; GUASSELLI, L.; QUEVEDO, R.; RUIZ, L.; BRESSANI, L.; RIFFEL, E. Identificação e análise de áreas suscetíveis a fluxos de detritos na bacia hidrográfica do Rio Taquari-Antas, RS. Pesquisas em Geociências, v. 45(2), e0732, 2018. http://dx.doi.org/10.22456/1807-9806.88685

PAIXÃO, M. A.; KOBIYAMA, M.; ZAMBRANO, F. C.; MICHEL, G. P.; FAN, F. M. Lições sobre o gerenciamento de desastres hidrológicos obtidas a partir da ocorrência em Rolante/RS. Revista gestão e sustentabilidade ambiental, v. 7, n. esp., p. 251-267, 2018. http://dx.doi.org/10.19177/rgsa.v7e02018251267

PRIETO, C. C. Previsão de deslizamentos em encostas por meio de modelagem numérica: estudo de caso na bacia Piracuama, município de Campos do Jordão, SP. 2018. 209 p. Tese (Doutorado em Ciência do Sistema Terrestre) - Instituto Nacional de Pesquisas Espaciais (INPE), São José dos Campos, 2018. Disponível em: 〈http://urlib.net/rep/8JMKD3MGP3W34P/3QBPA5E〉.

POKHAREL, B.; ALTHUWAYNEE, O. F.; AYDDA, A. et al. Spatial clustering and modelling for landslide susceptibility mapping in the north of the Kathmandu Valley, Nepal. Landslides, 2020. https://doi.org/10.1007/s10346-020-01558-5.

PSOMIADIS, E.; PAPAZACHARIOU, A.; SOULIS, K.X.; ALEXIOU, DS.; CHARALAMPOPOULOS, I. Landslide Mapping and Susceptibility Assessment Using Geospatial Analysis and Earth Observation Data. Land, v.9, v. 5, 133, 2020. https://doi.org/10.3390/land9050133

QUEVEDO, R. P. Mapeamento de suscetibilidade a movimentos de massa a partir de aprendizado de máquina. 2019. 71p. Dissertação de Mestrado, Programa de Pós Graduação em Sensoriamento Remoto, Universidade Federal do Rio Grande do Sul. 2019.

REGMI, N. R.; GIARDINO, J. R.; VITEK, J. D. Assessing susceptibility to landslides: Using models to understand observed changes in slopes. Geomorphology, v. 122, p. 25-38, 2010. http://dx.doi.org/10.1016/j.geomorph.2010.05.009

RUBIRA, F. G.; BARREIROS, A. M.; VILlELA, F. N. J.; PEREZ FILHO, A. Sistemas pedogeomorfológicos na interpretação da evolução de paisagens quaternárias em climas tropicais úmidos. Mercator, v.18, 2019. https://doi.org/10.4215/rm2019.e18020

RIFFEL, E. S.; RUIZ, L. F. C.; GUASSELLI, L. A. Mapeamento de suscetibilidade a deslizamentos a partir da mineração de dados e do modelo SHALSTAB. Revista Brasileira de Cartografia, v. 68, p. 1805-1818. 2016.

ROSSATO, M. S. Os climas do Rio grande do Sul: Variabilidade, tendências e tipologia. Tese (Doutorado em Geografia), Universidade Federal do Rio Grande do Sul, Porto Alegre, 253p. 2011.

SEMA; GPDEN/IPH/UFRGS Diagnóstico preliminar. Departamento de Recursos Hídricos da SEMA e Grupo de Pesquisa em Desastres Naturais do IPH/UFRGS. Porto Alegre: DRH/SEMA, 26p. 2017. Disponível em http://www.rs.gov.br/upload/20170125183225diagnostico_preliminar_gt_rolante _revfinal.pdf

TANG, RX., KULATILAKE, P. H. S. W., YAN, EC.; CAI, JS. et al. Evaluating landslide susceptibility based on cluster analysis, probabilistic methods, and artificial neural networks. Bull Eng Geol Environ, v.79, p.2235-2254, 2020. https://doi.org/10.1007/s10064-019-01684-y 
VAN DEN EECKHAUT M.; HERVÁS, J. State of the art of national landslide databases in Europe and their potential for assessing landslide susceptibility, hazard and risk. Geomorphology v.139, p.545-558, 2012. http://dx.doi.org/10.1016/j.geomorph.2011.12.006

VAN WESTEN, C. J.; VAN ASCH, T. W. J.; SOETERS, R. Landslide hazard and risk zonation-why is it still so difficult? Bull Eng Geol Env, v. 65, p.167-184, 2006. http://dx.doi.org/10.1007/s10064-005-0023-0

VANACÔR, R. N.; ROLIM, S. B. A. Mapeamento de susceptibilidade a deslizamentos usando técnicas de estatística bivariada e sistema de informações geográficas na região nordeste do Rio Grande do Sul. Revista Brasileira de Geomorfologia, v. 13 (1) p. 15-28. 2012. http://dx.doi.org/10.20502/rbg.v13i1.338

VARNES D. J. Slope movement types and processes. In Schuster R L, Krizek R J (eds.) Landslides Analysis and Control. Transportation Research Board Special Report, National Academy of Sciences, Washington D.C. v. 176, p. 11-33. 1978.

WAN, S.; CHANG, SH.; CHOU, TY.; SHIEN, C. M. A Study of Landslide Image Classification through Data Clustering using Bacterial Foraging Optimization. Journal of Chinese Soil and Water Conservation, v.49, n. 3, p.187-198, 2018. http://dx.doi.org/10.29417/JCSWC.201809_49(3).0006

WANG, Q.; WANG, Y.; NIU, R.; PENG, L. Integration of Information Theory, K-Means Cluster Analysis and the Logistic Regression Model for Landslide Susceptibility Mapping in the Three Gorges Area, China. Remote Sens., v. 9, p. 938, 2017. http://dx.doi.org/10.3390/rs9090938

WOODCOCK, N. H. Sizes of submarine slides and their significance: Journal of Structural Geology, v. 1, p. 137-142, 1979.

WOOTEN, R. M.; WITT, A. C.; MINIAT, C. F.; HALES, T. C.; ALDRED, J. L. Frequency and Magnitude of Selected Historical Landslide Events in the Southern Appalachian Highlands of North Carolina and Virginia: Relationships to Rainfall, Geological and Ecohydrological Controls, and Effects. Springer International Publishing Switzerland 2016203 C.H. Greenberg, B.S. Collins (eds.), Natural Disturbances and Historic Range of Variation, Managing Forest Ecosystems 32, 2016. DOI 10.1007/978-3-319-21527-3_9.

YALCIN, A. GIS-based landslide susceptibility mapping using analytical hierarchy process and bivariate statistics in Ardesen (Turkey): Comparisons of results and confirmations. CATENA, v. 72, p. 1-12, 2008. http://dx.doi.org/10.1016/j.catena.2007.01.003

ZÊZERE, J. L. Dinâmica de vertentes e riscos geomorfológicos. Centro de Estudos Geográficos Área de Geografia Física e Ambiente. Relatório n. 41, Lisboa, 129p. 2005.

ZHAO, F., MENG, X., ZHANG, Y., CHEN, G., SU, X., YUE, D. Landslide susceptibility mapping of Karakorum Highway combined with the application of SBAS-InSAR technology. Sensors, v. 19, p.26-85, 2019. DOI: 10.3390/s19122685. http://dx.doi.org/10.3390/s19122685 